\title{
The C1q family of proteins: insights into the emerging non-traditional functions
}

\author{
Berhane Ghebrehiwet ${ }^{1}{ }^{*}$, Kinga K. Hosszu ${ }^{1}$, Alisa Valentino ${ }^{1}$ and Ellinor I. B. Peerschke ${ }^{2}$ \\ ${ }^{1}$ The Department of Medicine, Stony Brook University, Stony Brook, NY, USA \\ ${ }^{2}$ The Department of Laboratory Medicine, Memorial Sloan-Kettering Cancer Center, New York, NY, USA
}

\section{Edited by:}

Uday Kishore, Brunel University, UK

\section{Reviewed by:}

Uday Kishore, Brunel University, UK

Annapurna Nayak, Brunel University, UK

\section{${ }^{*}$ Correspondence:}

Berhane Ghebrehiwet, Health Sciences Center, Stony Brook University School of Medicine, T-16 Room 040, Stony Brook, New York, NY 11794-8161, USA.

e-mail:berhane.ghebrehiwet@ stonybrook.edu

\begin{abstract}
Research conducted over the past 20 years have helped us unravel not only the hidden structural and functional subtleties of human $\mathrm{C} 1 \mathrm{q}$, but also has catapulted the molecule from a mere recognition unit of the classical pathway to a well-recognized molecular sensor of damage-modified self or non-self antigens. Thus, $\mathrm{C} 1 \mathrm{q}$ is involved in a rapidly expanding list of pathological disorders - including autoimmunity, trophoblast migration, preeclampsia, and cancer. The results of two recent reports are provided to underscore the critical role C1q plays in health and disease. First is the observation by Singh et al. (2011) showing that pregnant $\mathrm{C} 1 \mathrm{q}-/-$ mice recapitulate the key features of human preeclampsia that correlate with increased fetal death. Treatment of the C1q-/- mice with pravastatin restored trophoblast invasiveness, placental blood flow, and angiogenic balance and, thus, prevented the onset of preeclampsia. Second is the report by Hong et al. (2009) which showed that $\mathrm{C} 1 \mathrm{q}$ can induce apoptosis of prostate cancer cells by activating the tumor suppressor molecule WW-domain containing oxydoreductase (WWOX or WOX1) and destabilizing cell adhesion. Downregulation of $\mathrm{C} 1 \mathrm{q}$ on the other hand, enhanced prostate hyperplasia and cancer formation due to failure of WOX1 activation. C1q belongs to a family of structurally and functionally related TNF- $\alpha$-like family of proteins that may have arisen from a common ancestral gene. Therefore $\mathrm{C} 1 \mathrm{q}$ not only shares the diverse functions with the tumor necrosis factor family of proteins, but also explains why $\mathrm{C} 1 \mathrm{q}$ has retained some of its ancestral "cytokine-like" activities. This review is intended to highlight some of the structural and functional aspects of $\mathrm{C} 1 \mathrm{q}$ by underscoring the growing list of its non-traditional functions.
\end{abstract}

Keywords: role of C1q in inflammation and autoimmunity, C1q and cancer, emerging role of C1q, functions of C1q

\section{INTRODUCTION}

The first component of complement, C1, is a multimolecular complex comprising of $\mathrm{Clq}$ and a $\mathrm{Ca}^{2+}$-dependent tetramer, $\mathrm{Clr}_{2}-\mathrm{C} 1 \mathrm{~s}_{2}$. The role of $\mathrm{C} 1 \mathrm{q}$ within this complex is to serve as a recognition signal - a signal that is readily translated into a highly specific and orderly intramolecular rearrangement resulting in a sequential proteolytic activation - first of C1r and then of C1s thereby triggering activation of the classical pathway (Cooper, 1985; Schumaker et al., 1987; Arlaud et al., 2001). However, the role of $\mathrm{Clq}$ is not restricted to recognition of immune complexes or other molecules that activate the classical pathway. Evidence accumulated to date clearly demonstrates that $\mathrm{C} 1 \mathrm{q}$ is a key player in a rapidly expanding list of pathophysiological conditions which include: trophoblast invasion and placental development (Agostinis et al., 2010), onset of preeclampsia (Singh et al., 2011), regulation of autoimmune diseases such systemic lupus erythematosus (SLE; Walport et al., 1998) and activation of the tumor suppressor molecule WW-domain containing oxydoreductase, which plays a

Abbreviations: $\mathrm{cClq}$, the collagen domain of $\mathrm{Cl} q$; $\mathrm{cClqR}$, receptor for $\mathrm{cClq}$; CRT (identical to $\mathrm{cClqR}$ ), calreticulin; gClq, the globular heads of $\mathrm{Clq}$; gClqR, receptor for gClq; ghA, ghB, and ghC, globular heads of the $\mathrm{A}, \mathrm{B}$, and $\mathrm{C}$ chains of $\mathrm{Clq}$ respectively. critical role in the pathogenesis of prostate cancer (Hong et al., 2009).

Unlike most of the complement proteins, which by and large are synthesized in the liver, $\mathrm{Clq}$ is synthesized extrahepatically by a wide range of cell types including monocytes/macrophages (Bensa et al., 1983; Loos, 1983; Tenner and Volkin, 1986; Kolosov et al., 1996; Armbrust et al., 1997), epithelial cells (Colten, 1976) mesenchymal cells (Morris et al., 1978), dendritic cells (Vegh et al., 2003; Castellano et al., 2004a), trophoblasts (Bulla et al., 2008; Agostinis et al., 2010), microglial cells (Lynch et al., 2004; Farber et al., 2009), fibroblasts (Reid and Solomon, 1977; Skok et al., 1981; Gulati et al., 1993), and endothelial cells (Bulla et al., 2008; Bossi et al., 2011). The synthesized molecule in turn, is either transiently expressed as a cell membrane associated molecular ligand (mC1q; Loos, 1983), or secreted into the pericellular milieu where it can modulate cell-specific biological responses in a manner that involves an autocrine and/or paracrine signaling through cell surface receptors and their signaling partners (Menzies et al., 2008). The diversity of immunological functions mediated by $\mathrm{C} 1 \mathrm{q}$ could perhaps be explained by having a unique structural feature: a collagen-like domain (cClq) and a globular heads domain (gClq) present in the same protein. This paper will shed some light into the evolution and structural 
basis of C1q function and highlight some of its emerging novel functions.

\section{STRUCTURE OF HUMAN C1q}

Human C1q $(460 \mathrm{kDa})$ is a collagen-like, structurally complex, hexameric glycoprotein, which associates with the $\mathrm{Ca}^{2+}$ dependent $\mathrm{C}_{1} \mathrm{r}_{2}-\mathrm{C} 1 \mathrm{~s}_{2}$ tetramer $(360 \mathrm{kDa})$ to form the pentameric $\mathrm{C} 1$, the first component of the serum complement system (Calcott and Müller-Eberhard, 1972; Reid and Thompson, 1983; Reid, 1989). It is composed of six globular "heads" linked via six collagen-like "stalks" to a fibril-like central region (Shelton et al., 1972; Svehag et al., 1972; Knobel et al., 1975; Brodsky-Doyle et al., 1976; Sellar et al., 1991). The C1q molecule (Figure 1), consists of 3 remarkably similar but distinct polypeptide chains, A, B, and $\mathrm{C}$, each of which occurs 6 times in the molecule to give rise to a total of 18 chains $(6 \mathrm{~A}, 6 \mathrm{~B}, 6 \mathrm{C}$; Reid, 1989). The three chains are the product of three distinct genes, which are aligned $5^{\prime} \Rightarrow 3^{\prime}$, in the same orientation, in the order $\mathrm{A}-\mathrm{C}-\mathrm{B}$ on a $24-\mathrm{kb}$ stretch of DNA on chromosome 1p (Reid, 1985; Sellar et al., 1991). Each polypeptide chain $(\mathrm{A}=28 \mathrm{kDa}, \mathrm{B}=25 \mathrm{kDa}, \mathrm{C}=24 \mathrm{kDa})$ consists of 81 amino acid-long collagen-like $N$-terminal "stalk" and a $C$ terminal, globular "head" of 136 amino acids (Reid, 1989). The chains are arranged to form 6 triple helical strands, three peptide chains, A, B, and C, forming one strand (Figure 1). In each strand, the triple helix is formed between the $N$-terminal collagenlike sequences of the three chains while the globular "head" is formed from the $C$-terminal portion of these chains (Sellar et al.,
1991; Kishore and Reid, 1999). Chains A and B are disulfidelinked within a given strand through formation of disulfide bridges between the half-cysteine residues located at A-4 and B-4, whereas the $\mathrm{C}$ chain forms a disulfide bond with the $\mathrm{C}$ chain of the next strand through cysteine residues found at position C-4 (Reid, 1989). Thus, the two disulfide-linked strands form a doublet, and three doublets are linked by non-covalent forces to give $\mathrm{C} 1 \mathrm{q}$ its signature electron microscopic structure resembling a bouquet of tulips (Shelton et al., 1972; Brodsky-Doyle et al., 1976; Figure 1). Approximately $8 \%(\mathrm{w} / \mathrm{w})$ of human $\mathrm{Clq}$ is carbohydrate, which is in the form of glucosylgalactosyl disaccharide units linked to hydroxylysine residues in the $\mathrm{cClq}$ domain, and six asparaginelinked sugar chains located in the gC1q domain (Yonemasu et al., 1971; Calcott and Müller-Eberhard, 1972; Reid et al., 1972). The two types of sugars in turn account for approximately 69 and $31 \%$ of the total carbohydrate respectively (Mizuochi et al., 1979; Shinkai and Yonemasu, 1979; Reid, 1989).

From a structure-function point of view, the C1q molecule contains two very well defined major functional domains through which it enters into a wide range of molecular interactions. These domains are known as the collagen-like domain ( $c \mathrm{Clq}$ ), and the globular "heads" domain ( $g C 1 q$ ). Of these, the gC1q domain, which recognizes a wide range of molecular patterns including modifiedself and non-self antigens, is considered to be key to the versatility of C1q function (Gaboriaud et al., 2009). The two domains of C1q can be purified separately after the intact $\mathrm{Clq}$ molecule is first subjected to either peptic digestion at $\mathrm{pH} 4.45$, or collagenase digestion

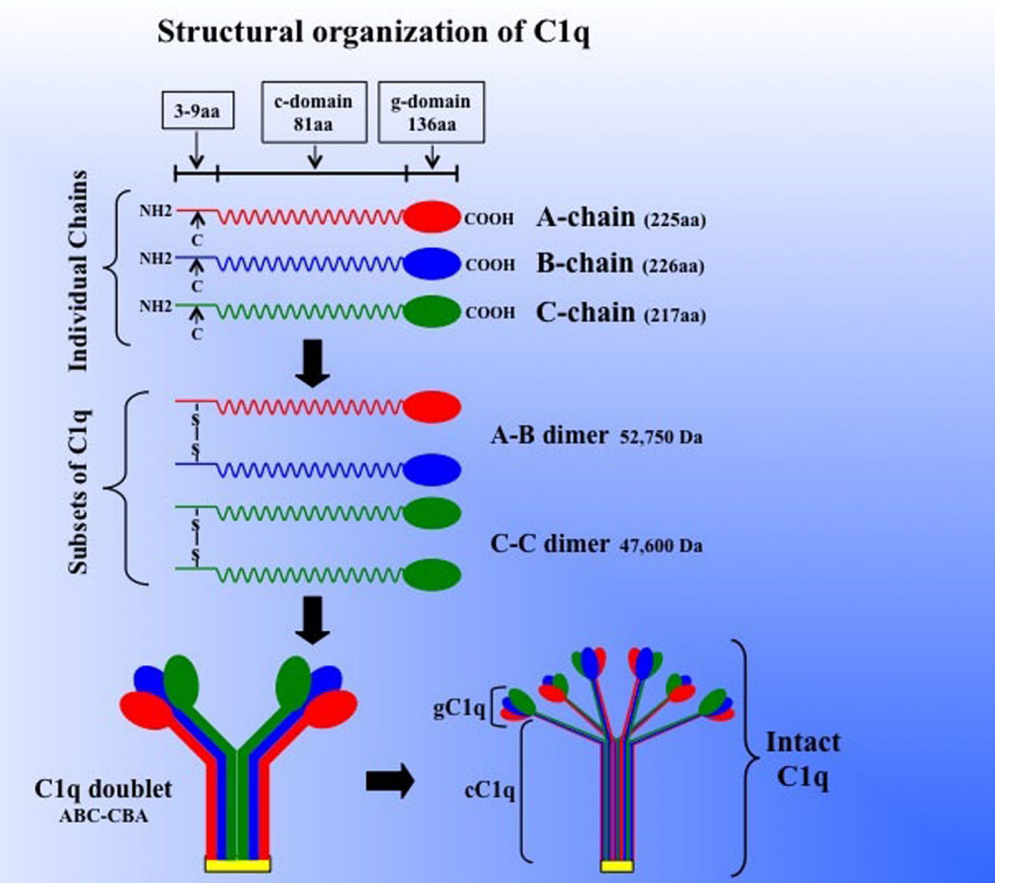

FIGURE 1 | Schematic model of the subunit structure and assembly of intact of C1q. Three similar chains - A, B, and C - are assembled to form disulfide-linked $A-B$ and $C-C$ dimers. One strand of the molecule consists of an $\mathrm{A}-\mathrm{B}$ dimer non-covalently linked to a $\mathrm{C}$ chain forming ( $\mathrm{A}-\mathrm{B}-\mathrm{C})$. The $\mathrm{C}$ chain of one strand is then disulfide-linked to the $C$ chain of a neighboring strand to give an A-B C-C B-A doublet and three such doublets are linked by non-covalent forces giving $\mathrm{C} 1 \mathrm{q}$ its final signature "bouquet-like" structure. The length of each chain as well as the length of the $\mathrm{gC} 1 \mathrm{q}$ and $\mathrm{cC} 1 \mathrm{q}$ domains (for brevity, g- or c-domain) is given in parenthesis. (The figure was adapted from Reid, 1989). 
at near neutral pH 7.4 (Knobel et al., 1974). The respective purified heterotrimeric domains can then be used in functional studies, although the affinity of the individual trimeric gC1q domain is likely to be several-fold less than that of the intact C1q because of the multivalency of the latter (Tacnet et al., 2008). Evidence accumulated to date convincingly shows that the two domains of $\mathrm{Clq}$ participate in a multiplicity of immunological functions by serving as a binding sites for a long list of pathogen-associated molecular patterns (PAMPs) as well as danger associated molecular patterns (DAMPs). These include viral proteins such as gp41 (Ebenbichler et al., 1991), acute phase proteins such as C-reactive protein (Jiang et al., 1991; Gewurz et al., 1993), bacterial and mitochondrial membranes (Gewurz et al., 1993), DNA (Jiang et al., 1991), as well as $\beta$-amyloid peptide (Jiang et al., 1994; Tacnet-Delorme et al., 2001). The gC1q domain has a heterotrimeric structure composed of the C-terminal halves of each of the three chains A, B, and C, and each of these heterotrimeric structures are postulated to function independently (Kishore and Reid, 1999, 2000). Because of the availability of recombinant forms of each of the globular heads (gh) or modules, it has now been possible to purify the individual modules (ghA, ghB, and ghC) as recombinant proteins and study their individual roles in ligand binding and biological function (Kishore et al., 2003; Ghai et al., 2007). Indeed, mutational studies using ghA, ghB, and ghC modules have identified the gh residues involved in recognition of IgG and IgM (Kojouharova et al., 2004; Gadjeva et al., 2008). In addition to recognition of self and non-self antigens, $\mathrm{Clq}$ can enter into a vast array of interactions by binding to cell surface molecules either via its $\mathrm{cClq}$ or $\mathrm{gClq}$ domain. $\mathrm{Clq}$ receptors mediate a plethora of immunologic functions including phagocytosis, and clearance of apoptotic cells (Bobak et al., 1987; Nauta et al., 2002; Païdassi et al., 2011).

Although the list of cell surface or cell associated molecules recognized by C1q is increasing, there are at least two well characterized and ubiquitously distributed cell surface molecules - known respectively as $\mathrm{cClqR}$ and $\mathrm{gClqR}$ - that recognize the two domains of C1q (Ghebrehiwet and Peerschke, 2004a). Although each of these molecules lacks a consensus sequence motif for a traditional transmembrane segment, the lack of direct conduit to intracellular signaling elements is circumvented by the formation of a docking/signaling complex with transmembrane proteins. This partnership in turn is dictated by the specific biological response to be induced (Ghebrehiwet et al., 2001; Ghebrehiwet and Peerschke, 2004a). Each of these receptors is a multiligand binding protein capable of inducing a wide range of cellular functions (Ghebrehiwet and Peerschke, 2004a). More importantly, binding of C1q to cell surfaces via either receptor induces a plethora of biological functions that play a critical role in innate and adaptive immunity, inflammation, infection, and cancer (Ghebrehiwet et al., 2001).

\section{THE C1q FAMILY OF PROTEINS}

From data available to date, it has become clear that the unusual feature of having a collagen-like and globular region in the same protein is not unique to C1q. Instead, the data show that C1q belongs to a long list of oligomeric proteins that are structurally and functionally similar. These proteins, whose members include: mannan-binding lectin $(M B L)$, lung surfactant protein A (SP-A), SP-D, collectin-43 (CL-43), collectin-46 (CL-46), and bovine conglutinin (Malhotra et al., 1992) are collectively known as collectins (collagen containing lectins) by virtue of having collagen-like sequences contiguous with non-collagen-like stretches (Hoppe and Reid, 1994). Collectins are calcium dependent molecules and belong to a group III of the family of lectins containing C-type carbohydrate recognition domains (CRD; Lu et al., 1993; Hakansson and Reid, 2000). Their genes characteristically contain a small exon encoding a 36 amino acid-long neck region, which links the collagen domain with the CRD. The CRD in turn, is responsible for recognition of glycoconjugates containing mannose and fucose on microorganisms but not on self-proteins, resulting in enhanced clearance of pathogenic microorganisms (Hakansson and Reid, 2000). Unlike the collectins however, C1q does not possess a consensus domain for CRD, but it shares another common feature with the collectins in that it possesses galactoseglucose disaccharides attached to the collagenous regions of each protein (Mizuochi et al., 1979; Reid, 1979; Shinkai and Yonemasu, 1979). Despite lacking a CRD domain however, recent data suggest that $\mathrm{Clq}$ also has lectin-like activity suggesting that carbohydrates - especially those on pathogens and apoptotic cells - may provide additional binding targets where the binding of $\mathrm{Clq}$ is critical for removal of self waste (Païdassi et al., 2008).

In addition to the collectins, several other molecules, which are structurally similar to $\mathrm{C} 1 \mathrm{q}$, have also been described. One of these is, adipocyte complement-related protein of $30 \mathrm{kDa}$ (ACRP30) or adiponectin (Scherer et al., 1995; Hu et al., 1996; Berg et al., 2001; Wong et al., 2004). ACRP30 or adiponectin, is secreted exclusively from fat cells and implicated in energy homeostasis and obesity as well as enhancement of hepatic insulin action (Berg et al., 2001; Wong et al., 2004). It is a protein of 247 amino acids consisting of an $\mathrm{N}$-terminal collagen-like domain and a $C$ terminal globular domain (Scherer et al., 1995; Berg et al., 2001). The globular domain shares a significant homology to the globular domains of type VIII and X collagens as well as subunits of C1q. More intriguing however is the fact that the crystal structure of a homotrimeric fragment from ACRP30 revealed an unexpected homology to the tumor necrosis factor (TNF) family of proteins. Because of identical folding topologies, key residue conservations, and similarity of trimer interfaces and intron positions, these studies have firmly established an evolutionary link between the TNF- $\alpha$ and the $\mathrm{Clq}$ family of proteins suggesting that TNF arose by divergence from an ancestral recognition molecule of the innate immune system (Shapiro and Scherer, 1998). The evolutionary connection between C1q-like proteins and TNF- $\alpha$, which control many aspects of inflammation, adaptive immunity, apoptosis, and energy homeostasis, not only sheds insight into the shared diverse functions of this family of proteins (Shapiro and Scherer, 1998), but also explains why $\mathrm{Clq}$ has retained some of its "cytokine-like" activities. Structurally, the C1q/TNF family of proteins contains the same compact "jellyroll" $\beta$ fold, usually organized as trimers but with diverse functions ranging from cytokine activity (TNF- $\alpha$ ), regulation of metabolism (ACRP30), connective tissue organization (collagen type VIII and X), cellular activation (CD40L), and innate immunity (C1q; Kishore et al., 2002, 2004; Gaboriaud et al., 2007). More recently, the crystal structure of the gC1q domain of $\mathrm{Clq}$ was solved and the structure reveals a compact, almost spherical heterotrimeric assembly held together mainly by non-polar 
interactions, with a $\mathrm{Ca}^{2+}$ ion bond at the top of the molecule (Gaboriaud et al., 2009). More importantly, the structural studies revealed that the heterotrimeric assembly of the gC1q domain appears to have unique features that allow its versatility (Gaboriaud et al., 2009). Other molecules in which the "gC1q domains" are found at the C-terminal end include: precerebellin (Kavety et al., 1994), multimerin (Hayward et al., 1995), and types VIII and X collagens (Bogin et al., 2002). Therefore, despite its similarities with the collectins, the structural folds of the gC1q domain, which are more similar to the TNF than to the CRD region of the collectins - make C1q more related to the TNF family of proteins (Kishore et al., 2004).

The significance of a particular human protein is sometimes underscored by the fact that pathogenic microorganisms specifically mimic its functional domain or antigenic determinant for the purpose of immune evasion and thus enhance their survival. For example, the three-dimensional structure of the major surface protein of Bacillus anthracis spore surface protein, bacillus collagenlike protein of anthracis (BclA) reveals remarkable similarity to $\mathrm{Clq}$ - although there is only low sequence identity between the two proteins (Sylvestre et al., 2002; Rety et al., 2005). Furthermore, both BclA and $\mathrm{Clq}$ have been shown to bind to lung alveolar surfactant component-SP-C, suggesting that both recognize common targets in the alveolar component (Rety et al., 2005). This molecular mimicry in turn, underscores not only the functional relevance of the gC1q domain, but also pathogenic microorganisms mimic this signature domain in order to get access into host cells. The exosporium of $B$. cereus, which belongs to the same genus of sporeforming aerobic bacteria as $B$. anthracis, contains a binding site for $\mathrm{gClqR}$. Although the nature of the B. cereus molecule has not been as yet identified, the fact that it recognizes gC1qR on cells for the initial spore attachment and entry suggests that this molecule may also contain a gC1q-like domain (Ghebrehiwet et al., 2009).

\section{THE DIVERSE BIOLOGICAL FUNCTIONS OF C1q}

Although for many years, the traditionally accepted role of $\mathrm{Clq}$ is the recognition of immune complexes and activation of the classical pathway, there is an ever-growing body of evidence, which suggests that $\mathrm{Clq}$ is a major sensor of DAMPs and PAMPS and plays a critical role in inflammation as well as innate and adaptive immunity (Figure 2) (Kojouharova et al., 2003; Sontheimer et al., 2005; Ghai et al., 2007; Gadjeva et al., 2008; Païdassi et al., 2008; Hosszu et al., 2010). In addition, C1q induces a plethora of immunologic functions by interaction with distinct cell surface molecules, which recognize either, its gC1q or $\mathrm{cClq}$ domain (Ghebrehiwet and Peerschke, 2004a). These cell surface molecules include cC1qR or calreticulin (CR), gC1qR (Malhotra et al., 1992; Ghebrehiwet and Peerschke, 2004a) CD93 (Nepomuceno et al., 1997; Steinberger et al., 2002), as well as other associated adapter molecules such as CD91 (Ogden et al., 2001; Gardai et al., 2003), CD44, DC-SIGN, and $\beta 1$ integrin (Feng et al., 2002; Menzies et al., 2008). Interaction of $\mathrm{Clq}$ with cell surface molecules, induces a wide range of biological responses including stimulation of leukocyte oxidative response (Tenner and Cooper, 1982), phagocytosis (Bobak et al., 1987), suppression of $\mathrm{B}$ and $\mathrm{T}$ cell proliferation (Ghebrehiwet et al., 1990), fibroblast and endothelial cell adhesion (Bordin et al., 1990; Chen et al., 1994; Feng et al., 2002), trophoblast

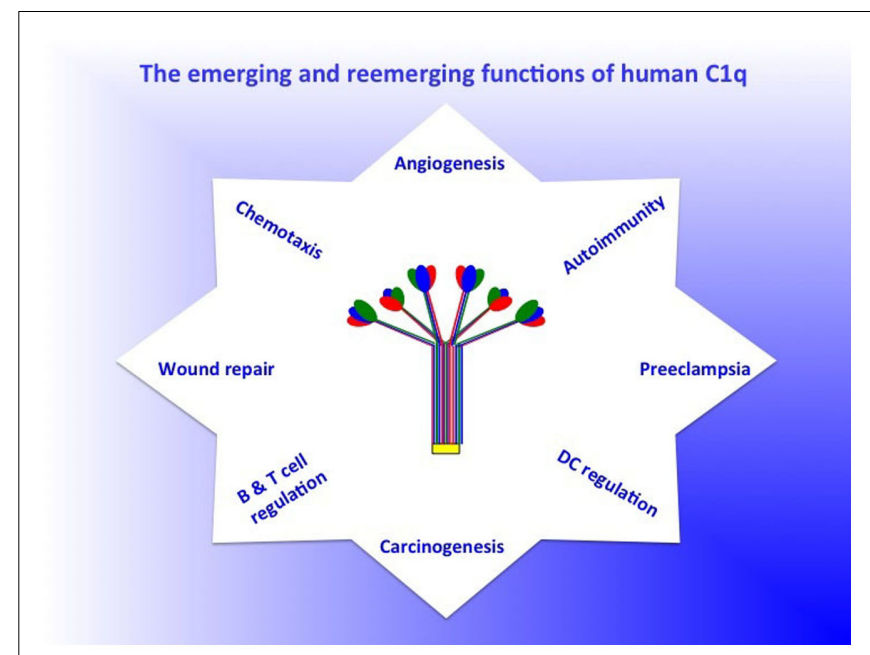

FIGURE 2 |The emerging and reemerging functions of C1q. The figure is intended not to a representative of the plethora of C1q-mediated functions, but rather is intended to highlight the growing list of emerging and reemerging non-traditional functions of $\mathrm{C} 1 \mathrm{q}$. For a more or less complete list of C1q functions see recent paper by Nayak et al. (2010).

cell migration (Agostinis et al., 2010), regulation of dendritic cells (Castellano et al., 2004a,b; Hosszu et al., 2010), angiogenesis (Bossi et al., 2011), and chemotaxis of eosinophils, mast cells, neutrophils, and dendritic cells (Ghebrehiwet et al., 1995; Kuna et al., 1996; Leigh et al., 1998; Vegh et al., 2005). Another interesting aspect of the $\mathrm{ClqRs}$, is that both are released into the pericellular milieu, by proliferating, activated, or proinflammatory cells. Because both are capable of activating the classical pathway, it is believed that the secreted molecules may exacerbate or trigger the local inflammatory process. The binding site for $\mathrm{gClqR}$ on $\mathrm{C} 1 \mathrm{q}$ has been shown to be on the A-chain of C1q (Ghebrehiwet et al., 2001), which is the same or overlapping site to a putative IgG site (Marques et al., 1993).

\section{C1q DEFICIENCY AND AUTOIMMUNITY}

The significance of $\mathrm{Clq}$ in health and disease is further underscored by the fact that deficiency in C1q leads to a plethora of diseases including recurrent infections, otitis media, meningitis, pneumonia (Nishino et al., 1981; Komatsu et al., 1982) as well as autoimmune diseases, a prototype of which is SLE. In fact, deficiency of $\mathrm{Clq}$ is considered to be a strong susceptibility factor for SLE as evidenced by the fact that almost all ( $\geq 92 \%)$ of the known patients with $\mathrm{Clq}$ deficiency have developed the disease (Botto et al., 1998; Walport et al., 1998; Pickering et al., 2000). The significance of C1q in SLE is further substantiated by the finding that, peripheral blood monocytes from SLE donors, who are not C1q deficient, have a significantly impaired ability to upregulate $\mathrm{C} 1 \mathrm{q}$ synthesis both at the mRNA and protein levels, when compared to their healthy counterparts (Moosig et al., 2006). Furthermore, previous studies have shown SLE patients to synthesize high levels of a non-functional, low molecular weight form of $\mathrm{Clq}$, that run with an apparent molecular weight of $150 \mathrm{kDa}$ by gel filtration (Hoekzema et al., 1985). This non-functional form of C1q 
is characterized by having an abnormal $\mathrm{A}-\mathrm{C}$ disulfide bonding instead of the normal pattern, which is $\mathrm{A}-\mathrm{B}$ and $\mathrm{C}-\mathrm{C}$ (Hoekzema et al., 1985, 1987, 1989). Although this form of C1q retains affinity for the $\mathrm{C}_{1} \mathrm{r}_{2} \mathrm{C} 1 s_{2}$-complex, it does not bind to the $\mathrm{Fc}$ in IgG aggregates (Martin and Loos, 1988). Because cultured monocytes from normal individuals can synthesize both the dysfunctional as well as the normal forms of $\mathrm{Clq}$, it is hypothesized that in disease states such as SLE, a condition may exist which favors a disproportionate concentration of dysfunctional C1q, especially since the normal $\mathrm{Clq}$ would be depleted due to complement activation (Hoekzema et al., 1985). Although the molecular underpinnings are still being worked out, two hypotheses have been put forth to explain the role of $\mathrm{C} 1 \mathrm{q}$ in SLE. The first deals with the role of $\mathrm{Clq}$ in removal of apoptotic waste. Removal of apoptotic cells and cellular debris is essential for maintenance of tissue homeostasis, organogenesis, remodeling, development, and maintenance of the immune system, protection against neoplasia, and resolution of inflammation. The mechanism of this removal involves the recognition of the apoptotic cell surface and initiation of phagocytic uptake by macrophages and dendritic cells. C1q, has been shown to play a major role both in the recognition and removal of apoptotic cells (Casciola-Rosen et al., 1994; Korb and Ahearn, 1997) through interaction with $\mathrm{Clq}$ receptors expressed both on the phagocytic cell (e.g., cC1qR/CD91; Ogden et al., 2001; Vandivier et al., 2002), and the apoptotic cell (phosphatidylserine, DNA, and possibly gC1qR; Païdassi et al., 2008). This in turn implies that defective clearance of immune complexes and apoptotic cells, leads to immune recognition of hidden epitopes - a critical immunopathogenic event leading to the development of SLE, the prototype autoimmune disease. Indeed, C1q directly and specifically binds to antigens expressed early on the surface of apoptotic cells through its gC1q domain (Korb and Ahearn, 1997; Païdassi et al., 2008) and the common autoantigens targeted in SLE, such as phosphatidylserine and DNA are found in high concentrations on the surface of apoptotic cells (Casciola-Rosen et al., 1994). However, while its role in removal of apoptotic debris is clearly important, there are a number of redundant pathways involved in the removal of self waste, thus making the role of C1q not as critical (Ghebrehiwet and Peerschke, 2004b). The second hypothesis stipulates that autoimmunity arising from the absence or inefficient $\mathrm{C1q}$ function, especially at local sites, reflects an important role in maintaining tolerance (Ghebrehiwet and Peerschke, 2004b; Hosszu et al., 2008, 2010). Thus, while C1q could provide active protection from autoimmunity by silencing or regulating autoreactive immune cells, its absence or defective secretion could lead to a loss of peripheral tolerance as a sum total of impaired apoptotic cell clearance and negative signaling (Hosszu et al., 2010). Inherent in this postulate is the notion that the unique structure of $\mathrm{Clq}$, which allows it to interact with its receptors via either its $\mathrm{cClq}$ or gC1q domain, may control the transition from the monocyte state (innate immunity) toward the professional antigen presenting cell (APCs) state (adaptive immunity). Therefore the recent observation showing that $\mathrm{C} 1 \mathrm{q}$ functions as a "molecular switch" during the narrow window of monocyte to DC transition (Hosszu et al., 2008, 2010), not only explains why C1q is primarily synthesized by potent APCs, but also underscores why its absence can impair antigen uptake and tolerance.

\section{LOCAL SYNTHESIS AND FUNCTION OF C1q}

As described above, most inflammatory cells such as those found in atherosclerotic plaques (Peerschke et al., 2004) or cells that undergo phenotypic differentiation or proliferation are known to express and/or secrete C1q (Vegh et al., 2003; Bulla et al., 2008; Hosszu et al., 2008). The emerging postulate is therefore, that locally secreted $\mathrm{Clq}$ modulates cellular function (s) by an autocrine and/or paracrine signaling mechanism. For example, fetal trophoblast cells invading the decidua in the early stages of pregnancy not only actively synthesize and express C1q on their surface, but this $\mathrm{C1q}$ is actively involved in promoting trophoblast invasion of the decidua (Agostinis et al., 2010). This in turn is mediated by two cell surface receptors $-\mathrm{gClqR}$ and $\alpha_{4} \beta_{1}$ integrin, which promote trophoblast adhesion and migration through the activation of ERK1/2 MAPKs (Agostinis et al., 2010). In support of this is the finding that $\mathrm{Clq}-/-$ mice manifested increased frequency of fetal resorption, reduced fetal weight, and smaller litter size when compared to their wild-type counterparts suggesting that defective local production of C1q may be involved in pregnancy disorders such as preeclampsia (Agostinis et al., 2010). The significance of C1q in pregnancy disorders is further supported by an independent study, which showed that pregnant $\mathrm{Clq}-/-$ mice express the key features of human preeclampsia that correlate with increased fetal death (Singh et al., 2011). Treatment of C1q-/mice with pravastatin restored trophoblast invasiveness, placental blood flow, and angiogenic balance and, thus, prevented the onset of preeclampsia (Singh et al., 2011). It is also important to note within this context, the results of recent studies, which showed that in vivo, $\mathrm{Clq}$ induces angiogenesis and promotes wound healing. This in turn identifies not only a novel role but also identifies $\mathrm{C} 1 \mathrm{q}$ as a potential pro-angiogenic molecule for the treatment of wounds and chronic ulcers (Bossi et al., 2011).

\section{THE EMERGING ROLE OF C1q IN CARCINOGENESIS}

Another emerging role of $\mathrm{Clq}$ is in the regulation of cancer cell survival and progression. Recent studies have shown that C1q, which is expressed on basal and epithelial cells of prostate tissues, sustains the activation of the tumor suppressor WOX1 (WWdomain containing oxydoreductase), which is needed for blocking cancer cell proliferation. This suggests that $\mathrm{Clq}$ may induce apoptosis of prostate cancer cells by activating WOX1 and destabilizing cell adhesion. Conversely, downregulation of $\mathrm{Clq}$ was found to enhance prostate hyperplasia and cancerous formation due to failure of WOX1 activation (Hong et al., 2009). More importantly, although $\mathrm{C} 1 \mathrm{q}$ is expressed in the normal prostate, it is significantly reduced in benign prostatic hyperplasia and prostate cancer tissues (Hong et al., 2009). Therefore, the C1q/WOX1-induced death of cancer cells could have a universal implication in cancer, as long as $\mathrm{C} 1 \mathrm{q}$ and WOX1 are present in both the extracellular and intracellular milieu, and are sufficient in activating the apoptotic cascade (Hong et al., 2009). However, since the autocrine or paracrine signaling effect of locally expressed $\mathrm{C} 1 \mathrm{q}$ is most likely going to be in concert with its cell surface receptors and signaling partners, it is important to note that both $\mathrm{cClqR} /$ calreticulin (cC1qR/CRT) and $\mathrm{gClqR}$ have also been implicated in carcinogenesis, albeit their roles seem to be rather divergent. Whereas cC1qR/CRT is reported to have tumor suppressive effect, $\mathrm{gClqR}$ appears to be 
requisite for tumor cell progression and metastasis. For example, when Epstein-Barr virus (EBV)-immortalized B lymphocytes were injected into nude mice, they were found to reproducibly inhibit tumor growth (Tosato et al., 2003). This anti-tumor activity, which is released by the lymphoblastic cells, was later identified to be a fragment of cClqR/CRT corresponding to the N-terminal residues $1-180$. Subsequently, recombinant protein corresponding to this $\mathrm{N}$-terminal fragment was found to inhibit endothelial cell proliferation in vitro and angiogenesis in vivo (Tosato et al., 2003). The inhibition of endothelial cell proliferation was due to direct binding of the $\mathrm{cClqR} / \mathrm{CRT}$ fragment to the extracellular matrix protein, laminin thereby interfering with endothelial cell attachment. Further studies showed that subcutaneous inoculation of recombinant CRT fragment into nude mice not only prevented the development of subcutaneous tumors, but also inhibited the growth of established ones (Tosato et al., 2003). Since the collagen tail of $\mathrm{Clq}(\mathrm{cClq})$ binds to the N-terminal half of $\mathrm{cClqR} / \mathrm{CRT}$, which contains several short (7-10 amino acids) $\mathrm{CH} 2$-like motifs (ExKxKx) similar to the $\mathrm{C} 1 \mathrm{q}$ binding motif found in the $\mathrm{CH} 2$ domain of IgG (Sontheimer et al., 2003), these C1q binding regions of $\mathrm{cClqR} / \mathrm{CRT}$ have the potential to be developed into therapeutic modalities.

The receptor for the ghs of $\mathrm{Clq}, \mathrm{gClqR}$, on the other hand, may have functions that enhance tumor growth and tumor progression. First, histochemical staining with anti gC1qR mAb revealed marked differential expression of gClqR in thyroid, colon, pancreatic, gastric, esophageal, and lung adenocarcinomas compared to the non-malignant histologic counterparts. In contrast, differential expression was not observed in endometrial, renal, and prostate carcinomas (Rubinstein et al., 2004; Peerschke et al., 2011). Recent studies not only corroborated these findings, but additionally showed that cell surface expressed $\mathrm{gClqR}$ is a receptor for the tumor homing peptide, LyP-1 (Fogal et al., 2008). Moreover, recent studies using human lung carcinoma A549 cells have shown the cell surface $\mathrm{gClqR}$ to be a key regulator for lamellipodia formation and cancer metastasis via receptor tyrosine kinase activation. Furthermore, the growth factor-induced lamellipodia formation

\section{REFERENCES}

Agostinis, C., Bulla, R., Tripodo, C., Gismondi, A., Stabile, H., Bossi, F., Guarnotta, C., Garlanda, C., De Seta, F., Spessotto, P., Santoni, A., Ghebrehiwet, B., Girardi, G., and Tedesco, F. (2010). An alternative role of C1q in cell migration and tissue remodelling: contribution to trophoblast invasion and placental development. J. Immunol. 185, 4420-4429.

Arlaud, G. J., Gaboriaud, C., Thielens, N. M., Rossi, V., Bersch, B., Hernandez, J.-F., and Fontecilla-Camps, J. C. (2001). Structural biology of $\mathrm{C} 1$ : dissection of a complex molecular machinery. Immunol. Rev. 180, 136-145.

Armbrust, T., Nordmann, B., Kreissig, M., and Ramadori, G. (1997). C1q synthesis by tissue mononuclear phagocytes from normal and from damaged rat liver: up-regulation by dexamethasone, down-regulation by interferon gamma, and lipopolysaccharide. Hepatology 26, 98-106.

Bensa, J. C., Reboul, A., and Colomb, M. G. (1983). Biosynthesis in vitro of complement subcomponents $\mathrm{Clq}$, $\mathrm{C} 1 \mathrm{~s}$ and $\mathrm{C} 1$-inhibitor by resting and stimulated human monocytes. Biochem. J. 216, 385-392.

Berg, A. H., Combs, T. P., Du, X., Brownlee, M., and Scherer, P. (2001). The adipocyte-secreted protein Acrp30 enhances hepatic insulin action. Nat. Med. 7, 947-953.

Bobak, D. A., Gaither, T. A., Frank, M. M., and Tenner, A. J. (1987). Modulation of FcR function by complement subcomponent $\mathrm{Clq}$ enhances the phagocytosis of IgG-opsonized targets by human monocytes and culture-derived

and cell migration were significantly decreased in gC1qR-depleted cells, with a concomitant blunt activation of the focal adhesion kinase and the respective receptor tyrosine kinases (Kim et al., 2001). These studies collectively suggest that $\mathrm{gC1qR}$, which is highly upregulated on the surface of tumor cells and inflammatory cell scan serve not only as a tumor cell marker, but also can be a target for therapeutic intervention (Peerschke et al., 2011).

\section{CONCLUDING REMARKS}

Because of the incredible number of reports that have come out in the past 20 years, it is not possible to list all the functions in which $\mathrm{C1q}$ is involved. Therefore, while touching on some of the well known functions of C1q, this paper underscores the role of $\mathrm{Clq}$ in novel and emerging areas of diseases (e.g., preeclampsia, cancer, and wound healing) in which either the soluble form or the membrane associated form of $\mathrm{Clq}$ appear to be intimately involved. The chimeric structure of $\mathrm{Clq}$ - containing two functional domains - together with the fact that it is synthesized by a wide range of proinflammatory cell types makes it likely that it is a potent orchestrator of molecular pathways involved not only in innate and adaptive immunity, but also in a wide range of inflammatory diseases including cancer. The heterotrimeric $\mathrm{gClq}$ domain of $\mathrm{C} 1 \mathrm{q}$ is also revealing itself as a powerful pattern recognition domain with the ability to sense a broad range of ligands - including a number of altered self-motifs and pathogenassociated molecular ligands - each of which will likely trigger a multiplicity of immunologic functions, which are either beneficial or deleterious to the host. More than ever, the availability of recombinant forms of the heterotrimeric trimeric $\mathrm{gClq}$ domains will undoubtedly help us gain insight into the mechanism of interaction between $\mathrm{Clq}$ and the vast array of molecular patterns. The best is yet to come.

\section{ACKNOWLEDGMENTS}

This work was supported in part by grants from the National Institutes of Health (R01 AI 060866 and R01 AI-084178).

macrophages. J. Immunol. 138, 1150-1156.

Bogin, O., Kvansakul, M., Rom, E., Singer, J., Yayon, A., and Hohenester, E. (2002). Insight into Schmid metaphyseal chondrodysplasia from the crystal structure of the collagen $\mathrm{X}$ NCI domain trimer. Structure 10, 165-173.

Bordin, S., Ghebrehiwet, B., and Page, R. C. (1990). Participation of C1q and its receptor in adherence of human diploid fibroblasts. J. Immunol. 145, 2520-2526.

Bossi, F., Rizzi, L., Bulla, R., Tripodo, C., Guarnota, C., Novati, F., Ghebrehiwet, B., and Tedesco, F. (2011). $\mathrm{Clq}$ induces in vivo angiogenesis, and wound healing. Mol. Immunol. 48, abstr. 1676.

Botto, M., Dell'Angola, C., Bygrave, A. E., Thompson, E. M., Cook, H. T.,
Petry, F., Loos, M., Pandolfi, P. P., and Walport, M. J. (1998). Homozygous Clq deficiency causes glomerulonephritis associated with multiple apoptotic bodies. Nat. Genet. 19, 56-59.

Brodsky-Doyle, B., Leonhard, K. R., and Reid, K. B. M. (1976). Circulardichroism and electron microscopy studies of human subcomponent $\mathrm{Clq}$ before and after limited proteolysis by pepsin. Biochem. J. 159, 279.

Bulla, R., Agostinis, C., Bossi, F., Rizzi, L., Debeus, A., Tripodo, C. Radillo, O., DeSeta, F., Ghebrehiwet, B., and Tedesco, F. (2008). Decidual endothelial cells express surface bound $\mathrm{Clq}$ as a molecular bridge between endovascular trophoblast and decidual endothelium. Mol. Immunol. 45, 2629-2640. 
Calcott, M. A., and Müller-Eberhard, H. J. (1972). C1q protein of human complement. Biochemistry 11, 3443.

Casciola-Rosen, L. A., Anhalt, G., and Rosen, A. (1994). Autoantigens targeted in systemic lupus erythematosus are clustered in two populations of surface structures on apoptotic keratinocytes. J. Exp. Med. 179. 1317-1330.

Castellano, G., Woltman, A. M., Nauta, A. J., Roos, A., Trouw, L. A., Seelen, M., Schena, F. B., Daha, M. R., and van Kooten, C. (2004a). Maturation of dendritic cells abrogates C1q production in vivo and in vitro. Blood 103, 3813-3820.

Castellano, G., Woltman, A. M., Schena, F. P., Roos, A., Daha, M. R., and van Kooten, C. (2004b). Dendritic cells and complement: at the crossroad of innate and adaptive immunity. Mol. Immunol. 41, 133-140.

Chen, A., Gaddipati, S., Volkman, D. J., Peerschke, E. I. B., and Ghebrehiwet, B. (1994). Human T cells possess specific receptors for $\mathrm{Clq}$ : role in activation and proliferation. $J$. Immunol. 153, 1430-1440.

Colten, H. R. (1976). Biosynthesis of complement. Adv. Immunol. 22, 67-118.

Cooper, N. R. (1985). The classical complement pathway: activation and regulation of the first complement component. Adv. Immunol.37, 151-216.

Ebenbichler, C. F., Thielens, N. M., Vornhagen, R., Marschang, P., Arlaud, G. J., and Dierich, M. P. (1991). Human immunodeficiency virus type 1 activates the classical pathway of complement by direct binding through specific sites in the transmembrane glycoprotein gp41. J. Exp. Med. 174, 1417-1424.

Farber, K., Cheung, G., Mitchell, D., Wallis, R., Weihe, E., Schwaeble, W., and Kettenmann, H. (2009). C1q, the recognition subcomponent of the classical pathway of complement, drives microglial activation. J. Neurosci. Res. 87, 644-652.

Feng, F., Tonnesen, M. G., Peerschke, E. I. B., and Ghebrehiwet, B. (2002). Cooperation of $\mathrm{Clq}$ receptors and integrins in C1q-mediated endothelial cell adhesion and spreading. $J$. Immunol. 168, 2441-2448.

Fogal, V., Zhang, L., Krajewski, S., and Ruoslahti, E. (2008). Mitochondrial/cell-surface protein p32/gClqR as a molecular target in tumor cells and tumor stroma. Cancer Res. 68, 7210-7218.

Gaboriaud, C., Juanhuix, J., Gruez, A., Lacroix, M., Darnault, C., Pignol, D., Verger, D., Fontecilla-Camps, J. C., and Arlaud, G. (2009). The crystal structure of the globular head of complement protein $\mathrm{Clq}$ provides a basis for its versatile recognition properties. J. Biol. Chem. 278, 46974-46982.

Gaboriaud, C., Païdassi, H., Frachet, P., Tacnet-Delorme, P., Thielens, N. M., and Arlaud, G. J. (2007). "Clq: a versatile pattern recognition molecule and sensor of altered self," in Collagen-Related Lectins in Innate Immunity, Vol. 81, ed. D. Kilpatrick (Research Signpost), 1-15.

Gadjeva, M. S., Rouseva, M. M., Zlatarova, A. S., Reid, K. B., Kishore, U., and Kojouharova, M. S. (2008). Interaction of human C1q with IgG and IgM: revisited. Biochemistry 47, 13093-13102.

Gardai, S. J., Xiao, Y. Q., Dickinson, M., Nick, J. A., Voelker, D. R., Greene, K. E., and Henson, P. M. (2003). By binding SIRPalpha or calreticulin/CD91, lung collectins act as dual function surveillance molecules to suppress or enhance inflammation. Cell 115, 13-23.

Gewurz, H., Ying, S.-C., Jiang, H., and Lint, T. F. (1993). Nonimmune activation of the classical complement pathway. Behring Inst. Mitt. 93, 138-147.

Ghai, R., Waters, P., Roumenina, L. T., Gadjeva, M., Kojouharova, M. S., Sim, R. S., Reid, K. B. M., and Kishore, U. (2007). Clq and its growing family. Immunobiology 212, 253-266.

Ghebrehiwet, B., Gruber, B., Kew, R. R., Marchese, M. J., Peerschke, E. I. B., and Reid, K. B. M. (1995). Murine mast cells express two types of $\mathrm{Clq}$ receptors that are involved in the induction of chemotaxis and chemokinesis. J. Immunol. 155, 2614-2619.

Ghebrehiwet, B., Habicht, G. S., and Beck, G. (1990). Interaction of $\mathrm{Clq}$ with its receptors on cultured cell lines induces an antiproliferative response. Clin. Immunol. Immunopathol. 54, 148-160.

Ghebrehiwet, B., Lim, B.-L., Feng, X., and Peerschke, E. I. B. (2001). $\mathrm{gClq}-\mathrm{R} / \mathrm{p} 33$, a member of a new class of multifunctional and multicompartmental cellular proteins, is involved in inflammation and infection. Immunol. Rev. 180, 65-77.

Ghebrehiwet, B., and Peerschke, E. I. B. (2004a). cClq-R (calreticulin) and gC1q-R/p33: ubiquitously expressed multi-ligand binding cellular proteins involved in inflammation and infection. Mol. Immunol. 41, 173-183.
Ghebrehiwet, B., and Peerschke, E. I. B. (2004b). "Role of C1q and C1q receptors in the pathogenesis of systemic lupus erythematosus," in Complement in Autoimmunity, Vol. 7, ed G. C. Tsokos (Basel: S. Karger AG), 87.

Ghebrehiwet, B., Tantral, L., Titmus, M. A., Panessa-Warren, B. J., Tortora, G. T., Wong, S. S., and Warren, J. B. (2009). The exosporium of $B$. cereus contains a binding site for $\mathrm{gclqr} / \mathrm{p} 33$ : implication in spore attachment and/or entry. Adv. Exp. Med. Biol. 598, 181-187.

Gulati, P., Lemercier, C., Guc, D., and Whaley, K. (1993). Regulation of the synthesis of $\mathrm{C} 1$ subcomponents and C1-inhibitor. Behring Inst. Mitt. 93 , 196-203.

Hakansson, K., and Reid, K. B. M. (2000). Collectin structure: a review. Protein Sci. 9, 1607-1617.

Hayward, C. P., Hassell, J. A., Denomme, G. A., Rachubinski, R. A., Brown, C., and Kelton, J. G. (1995). The cDNA sequence of human endothelial cell multimerin. a unique protein with RGDS, coiled-coil, and epidermal growth factor-like domains and a carboxyl terminus similar to the globular domain of complement C1q and collagen type VIII and X. J. Biol. Chem. 270, 18246-18251.

Hoekzema, R., Brouwer, M. C., de Graeff-Meeder, E. R., van Helden, H. T. P., and Hack, C. E. (1989). Biosynthesis of normal and low-molecularmass complement component $\mathrm{Cla}$ by cultured human monocytes and macrophages. Biochem. J. 257, 477-486.

Hoekzema, R., Brouwer, M. C., and Hack, C. E. (1987). Production of LWM-C1q by monocytes from SLE patients and normal individuals. Complement 4, 169.

Hoekzema, R., Hannema, A. J., Swaak, T. J. G., Paardekooper, J. Q., and Hack, C. E. (1985). Low molecular weight $\mathrm{Clq}$ in systemic lupus erythematosus. J. Immunol. 135, 265-271.

Hong, Q., Sze, C.-I., Lin, S.-R., Lee, M.H., He, R.-Y., Schultz, L., Chang, J.Y., Chen, S.-J., Boackle, R. J., Hsu, L.-J., and Chang, N.-S. (2009). Complement $\mathrm{Clq}$ activates tumor suppressor wwox to induce apoptosis in prostate cancer cells. PLoS ONE 4, e5755. doi:10.1371/journal.pone.0005755

Hoppe, H.-J., and Reid, K. B. M. (1994). Trimeric C-type lectin domains in host defence. Curr. Biol. 2, 1129.

Hosszu, K. K., Santiago-Schwarz, F., Peerschke, E. I., and Ghebrehiwet, B. (2008). Clq is a molecular switch dictating the monocyte to dendritic cell (DC) transition and arrests DCs in an immature phenotype. FASEB J. $22,673.1$

Hosszu, K. K., Santiago-Schwarz, F., Peerschke, E. I. B., and Ghebrehiwet, B. (2010). Evidence that a $\mathrm{Clq} / \mathrm{ClqR}$ system regulates monocyte-derived dendritic cell differentiation at the interface of innate and acquired immunity. Int. Immunol. 16, 115-127.

$\mathrm{Hu}$, E., Liang, P., and Spiegelman, P. M. (1996). AdipoQ is a novel adiposespecific gene dysregulated in obesity. J. Biol. Chem. 271, 10697-10703.

Jiang, H., Burdick, D., Glabe, C. G., Cotman, C. W., and Tenner, A. J. (1994). Beta amyloid activates complement by binding to a specific region of the collagen-like domain of the C1q A-chain. J. Immunol. 152, 5050-5059.

Jiang, H. X., Siegel, J. N., and Gewurz, H. (1991). Binding and complement activation by $\mathrm{C}$-reactive protein via the collagen-like region of $\mathrm{Clq}$ and inhibition of these reactions by monoclonal antibodies to C-reactive protein and C1q. J. Immunol. 146, 2324-2330.

Kavety, B., Jenkins, N. A., Fletcher C. F., Copeland, N. G., and Morgan, J. I. (1994). Genomic structure and mapping of precerebellin and a precerebellin-related gene. Brain Res. Mol. Brain Res. 27, 152-156.

Kim, K.-B., Yi, J.-S., Nguyen, N., Lee, J.-H., Kwon, Y.-C., Ahn, B.-Y., Cho, H., Kim, Y. K., Yoo, H.-J., Lee, J.S., and Ko, Y.-G. (2001). Cell-surface receptor for complement component $\mathrm{Clq}(\mathrm{gClqR})$ is a key regulator for lamellipodia formation and cancer metastasis. J. Biol. Chem. 286, 23093-23101.

Kishore, U., Gaboriaud, C., Waters, P., Shrive, A. K., Greenhough, T. J., Reid, K. B. M., Sim, R. B., and Arlaud, G. J. (2004). Clq and tumor necrosis factor superfamily: modularity and versatility. Trends Immunol. 25, 551-561.

Kishore, U., Gupta, S. K., Perdikoulis, M. D., Kojouharova, M. S., Urban, B. C., and Reid, K. B. M. (2003). Modular organization of the carboxyterminal globular head region of human $\mathrm{Clq} \mathrm{A}, \mathrm{B}$, and $\mathrm{C}$ chains. J. Immunol. 171, 812-820.

Kishore, U., Kojouharova, M. S., and Reid, K. B. M. (2002). Recent progress in the understanding of the structure-function relationships of the globular head region of C1q. Immunobiology 205, 355-364.

Kishore, U., and Reid, K. B. M. (1999). Modular organization of proteins containing $\mathrm{Clq}$-like globular 
domain. Immunopharmacology 42, 15-21.

Kishore, U., and Reid, K. B. M. (2000). C1q: structure, function and receptors. Immunopharmacology 49, 159-170.

Knobel, H. R., Heuser, C., Rodrick, M. L., and Isliker, H. (1974). Enzymatic digestion of the first component of human complement C1q. J. Immunol. 112, 2094-2101.

Knobel, H. R., Villiger, W., and Isliker, H. (1975). Chemical analysis and electron microscopy studies of human C1q prepared by different methods. Eur. J. Immunol. 5, 78.

Kojouharova, M. S., Gadjeva, M. D., Tzacheva, I. G., Zlatorova, A., Roumenina, L. T., Tchorbadjieva, M. I., Atanasov, B. P., Waters, P., Urban, B. C., Sim, R. B., Reid, K. B. M., and Kishore, U. (2004). Mutational analyses of the recombinant globular regions of human $\mathrm{ClqA}, \mathrm{B}$ and $C$ chains suggest an essential role for arginine and histidine residues in the C1q-IgG interaction. J. Immunol. 172, 4351-4358.

Kojouharova, M. S., Tsacheva, I. G., Tchorbadjieva, M. I., Reid, K. B. M., and Kishore, U. (2003). Localization of ligand-binding sites on human $\mathrm{Clq}$ globular head region using recombinant globular head fragments and single-chain antibodies. Biochim. Biophys. Acta 1652, 64-74.

Kolosov, M., Kolosova, I., Zhou, A., and Leu, R. W. (1996). Autocrine induction of macrophage synthesis of complement subcomponent $\mathrm{Clq}$ by endogenous interferonalpha/beta. J. Interferon Cytokine Res. 16, 209-215.

Komatsu, A., Komazawa, M., Murakami, M., and Nagaki, Y. (1982). A case of selective C1qdeficiency with SLE-like symptoms. J. Jpn. Pediatr. Soc. 86, 23-27.

Korb, L. C., and Ahearn, J. M. (1997). C1q binds directly and specifically to surface blebs of apoptotic human keratinocytes: complement deficiency and systemic lupus erythematosus revisited. J. Immunol. 158, 4527-4529.

Kuna, P., Iyer, M., Peerschke, E. I. B., Kaplan, A. P., Reid, K. B. M., and Ghebrehiwet, B. (1996). Human $\mathrm{C} 1 \mathrm{q}$ induces eosinophil migration. Clin. Immunol. Immunopathol. 81, 48-54.

Leigh, L. E., Ghebrehiwet, B., Perera, T. P., Bird, I. N., Strong, P., Kishore, U., Reid, K. B. M., and Eggleton, P. (1998). Clq-mediated chemotaxis by human neutrophils: involvement of gClqR and G-protein signalling mechanisms. Biochem. J. 330, 247-254.

Loos, M. (1983). Biosynthesis of the collagen-like C1q molecule and its receptor function for $\mathrm{Fc}$ and polyanionic molecules on macrophages. Curr. Top. Microb. Immunol. 102, $1-56$.

Lu, J., Wiedemann, H., Timpl, R., and Reid, K. B. M. (1993). Similarity in structure between $\mathrm{Clq}$ and the collectins as judged by electron microscopy. Behring Inst. Mitt. 93, 6-16.

Lynch, N. J., Willis, C. L., Nolan, C. C., Roscher, S., Fowler, M. J., Weihe, E., Ray, D. E., and Schwaeble, W. J. (2004). Microglial activation and increased synthesis of complement component $\mathrm{Clq}$ precedes bloodbrain barrier dysfunction in rats. Mol. Immunol. 40, 709-716.

Malhotra, R., Lu, J., Thiel, S., Jensenius, J.-C., Willis, A. C., and Sim, R. B. (1992). Clq receptor (collectin receptor): primary structure, homology, and interaction with ligands. Immunobiology 184, 437.

Marques, G. J., Anton, L. C., Barrio, E., Sanchez, A., Ruiz, S., Gavilanes, F., and Vivanco, F. (1993). Arginine residues of the globular regions of human $\mathrm{Clq}$ involved in the interaction with immunoglobulin G. J. Biol Chem. 268, 10393-10402.

Martin, H., and Loos, M. (1988). Guinea pig macrophages synthesize a low molecular weight form of $\mathrm{Clq}$ with affinity for the C1r2C1s2-complex but which does not bind to Fc in immunoglobulin aggregates. Mol. Immunol. 25, 1231-1237.

Menzies, C. A., Habiel, D., Glassberg, P. F., Nguyen, P. P., Jesty, P., Peerschke, E. I. B., and Ghebrehiwet, B. (2008). Identification of $\mathrm{Clq}$ receptor associated surface molecules on the monocyte-like cell line U937. FASEB J. 22, abstr. 673.3.

Mizuochi, T., Yonemasu, K., Yamashita, K., and Kobata, A. (1979). The asparagine-linked sugar chains of subcomponent Clq of the first component of human complement. J. Biol. Chem. 253, 7407-7409.

Moosig, F., Damm, F., Knorr-Spar, A., Ritgen, M., Zeuner, R. A., Kneba, M., Emst, M., and Schröder, J. O. (2006). Reduced expression of C1qmRNA in monocytes from patients with systemic lupus erythematosus. Clin. Exp. Immunol. 146, 409-416.

Morris, K. M., Colten, H. R., and Bing, D. H. (1978). The first component of complement. a quantitative comparison of its biosynthesis in culture by human epithelial and mesenchymal cells. J. Exp. Med. 148, 1007-1019.
Nauta, A. J., Touw, L. A., Daha, M. R., Tijsma, O., Nieuwland, R., Schwaeble, W. J., Gingras, A. R., Mantovani, A., Hack, E. C., and Roos, A. (2002). Direct binding of Clq to apoptotic cells and cell blebs induces complement activation. Eur. J. Immunol. 32, 1726-1736.

Nayak, A., Ferluga, J., Tsolaki, A. G., and Kishore, U. (2010). The non-classical functions of the classical complement pathway recognition subcomponent C1q. Immunol. Lett. 131, 139-150.

Nepomuceno, R. R., Henschen, E. A., Burgess, W. H., and Tenner, A. J. (1997). cDNA cloning and primary structure analysis of ClqR (P), the human C1q/MBL/SPA receptor that mediates enhanced phagocytosis in vitro. Immunity 6 , 119-129.

Nishino, H., Shibuya, K., Nishida, Y., and Mushimoto, M. (1981). Lupus erythematosus-like syndrome with selective C1q complete deficiency of C1q. Ann. Intern. Med. 95, 322-324.

Ogden, C. A., deCathelineau, A., Hoffmann, P. R., Braton, D., Ghebrehiwet, B., Fadok, V. A., and Henson, P. M. (2001). Clq and mannose binding lectin (MBL) engagement of cell surface calreticulin and CD91 initiates macropinocytosis and uptake of apoptotic cells. J. Exp. Med. 194, 781-795.

Païdassi, H., Tacnet, P., Garlatti, V., Darnault, C., Ghebrehiwet, B., Gaboriaud, C., Arlaud, G. J., and Frachet, P. (2008). C1q binds phosphatidylserine and likely acts as a multiligand bridging molecule in apoptotic cell recognition. J. Immunol. 180, 2329-2338.

Païdassi, H., Tacnet-Delorme, P., Verneret, M., Gaboriaud, C., Houen, G., Duus, K., Ling, W. L., Arlaud, G. J., and Frachet, P. (2011). Investigations on the Clqcalreticulin-phosphatidylserine interactions yield new insights into apoptotic cell recognition. J. Mol. Biol. 408, 277-290.

Peerschke, E. I. B., Dembitzer, F. R., Kinoshita, Y., Burstein, D., Phelps, R., and Ghebrehiwet, B. (2011). Differential expression of $\mathrm{gClqR}$ in normal and pathologic human tissue. Mol. Immunol. 48, abstr. 1718.

Peerschke, E. I. B., Minta, J. O., Zhou, S. Z., Bini, A., Gotlieb, A., Colman, R. W., and Ghebrehiwet, B. (2004). gClq-R/p33 expression on human coronary artery atherosclerotic lesions. Mol. Immunol. 41, 759-766.

Pickering, M. C., Botto, M., Taylor, P. R., Lachmann, P. J., and Walport,
M. J. (2000). Systemic lupus erythematosus, complement deficiency, and apoptosis. Adv. Immunol. 76, 227-234.

Reid, K. B. M. (1979). Complete amino acid sequences of the three collagenlike regions present in subcomponent $\mathrm{Clq}$ of the first component of human complement. Biochem. J. 179, 367-371.

Reid, K. B. M. (1985). Molecular cloning and characterization of the complementary DNA and gene coding for the B chain subcomponent $\mathrm{Clq}$ of the human complement system. Biochem. J. 231, 729.

Reid, K. B. M. (1989). Clq: genes, biosynthesis and biology. Behring Inst. Mitt. 84, 8-19.

Reid, K. B. M., Lowe, D. M., and Porter, R. R. (1972). Isolation and characterization of $\mathrm{Clq}$, a subcomponent of the first component of complement, from human and rabbit sera. Biochem. J. 130, 749-763.

Reid, K. B. M., and Solomon, E. (1977). Biosynthesis of the first component of complement by human fibroblasts. Biochem. J. 167, 647-660.

Reid, K. B. M., and Thompson, R. A. (1983). Characterization of nonfunctional form of $\mathrm{Clq}$ found in patients with genetically linked deficiency of C1q activity. Immunology 20, 1117-1125.

Rety, S., Salamitou, S., Garcia-Verdugo, I., Hulmes, D. J. S., Le Hagarat, F., Chaby, R., and Lewit-Bentley, A. (2005). The crystal structure of the Bacillus anthracis spore surface protein, BclA, shows remarkable similarity to mammalian proteins. J. Biol. Chem. 280, 43073-43078.

Rubinstein, D. B., Stortchevoi, A., Boosalis, M., Ashfaq, R., Ghebrehiwet, B., Peerschke, E. I. B., Calvo, F., and Gillaume, T. (2004). Receptor for the globular heads of Clq (gClqR; p33; hyaluronan-binding protein) is preferentially expressed by adenocarcinoma cells. Int. J. Cancer 110, 741-750.

Scherer, P. E., Williams, S., Fogliano, M., Baldini, G., and Lodish, H. F. (1995). A novel serum protein similar to $\mathrm{Clq}$, produced exclusively in adipocytes. J. Biol. Chem. 270, 26746-26749.

Schumaker, V. N., Zavodsky, P., and Poon, P. H. (1987). Activation of the first component of complement. Annu. Rev. Immunol. 5, 21-42.

Sellar, G. C., Blake, D. J., and Reid, K. B. M. (1991). Characterization and organization of the genes encoding the A-, B-, and C- chains of 
human complement subcomponent C1q. Biochem. J. 274, 481.

Shapiro, L., and Scherer, P. E. (1998). The crystal structure of a complement-1q family of protein suggests an evolutionary link to tumor necrosis factor. Curr. Biol. 8, 335-338.

Shelton, E., Yonemasu, K., and Stroud, R. M. (1972). Ultrastructure of the human complement component C1q. Proc. Natl. Acad. Sci. U.S.A. 69, 65-68.

Shinkai, H., and Yonemasu, K. (1979). Hydroxylysine-linked glycosides of human complement subcomponent $\mathrm{Clq}$ and of various collagens. Biochem. J. 177, 847-852.

Singh, J., Ahmed, A., and Girardi, G. (2011). Role of complement component $\mathrm{Clq}$ in the onset of preeclampsia in mice. Hypertension 58, 716-724.

Skok, J., Solomon, E., Reid, K. B. M., and Thompson, R. A. (1981). Distinct genes for fibroblast and serum C1q, Nature 292, 549-551.

Sontheimer, R. D., Racila, D., Racila, E., Eggleton, P., and Donnelly, S. (2003). "Calreticulin's role(s) in autoimmune disorders," in Calreticulin, 2nd Edn, eds P. Eggleton and M. Michalak (New York: Eurekah.com and Kluwer Academic/Plenum Publishing), 180-192.

Sontheimer, R. D., Racila, E., and Racila, D. M. (2005). C1q: its functions within the innate and adaptive immune responses and its role in lupus autoimmunity. J. Invest. Dermatol. 125, 14-23.
Steinberger, A. S., Wille, S., Stöckl, J., Selenko, N., Prager, E., Staffler, G., Madic, O., Stockinger, H., and Knapp, W. (2002). Identification of human CD93 as the phagocytic $\mathrm{Clq}$ receptor $(\mathrm{ClqRp})$ by expression cloning. J. Leukoc. Biol. 71, 133-140.

Svehag, S. E., Manheim, L., and Bloth, B. (1972). Ultrastructure of human Clq protein. Nature New Biol. 238, 117.

Sylvestre, P., Couture-Tosi, E., and Mock, M. (2002). A collagen-like surface structure glycoprotein is a structural component of the Bacillus anthracis exosporium. Mol. Microbiol. 45, 169-178.

Tacnet, P., Cheong, E. C. C., Goeltz, P., Ghebrehiwet, B., Arlaud, G. J., Liu, X.-Y., and Lesieur, C. (2008). Trimeric reassembly of the globular domain of human Clq. Biochim. Biophys. Acta 1784, 518-529.

Tacnet-Delorme, P., Chevallier, S., and Arlaud, G. J. (2001). Beta-amyloid fibrils activate the $\mathrm{Cl}$ complex of complement under physiological conditions: evidence for a binding site for A beta on the $\mathrm{Clq}$ globular regions. J. Immunol. 167, 6374-6638.

Tenner, A. J., and Cooper, N. R. (1982). Stimulation of a human polymorphonuclear leukocyte oxidative response by the $\mathrm{Clq}$ subunit of the first component of complement. J. Immunol. 128, 2547-2552.
Tenner, A. J., and Volkin, D. B. (1986). Complement subcomponent $\mathrm{Clq}$ secreted by cultured human monocytes has a subunit structure identical with that of serum C1q. Biochem. J. 233, 451-458.

Tosato, G., Yao, L., and Pike, S. E. (2003). "Calreticulin and tumor suppression," in Calreticulin, 2nd Edn, eds P. Eggleton and M. Michalak (New York: Eurekah.com and Kluwer Academic/Plenum Publishing), 161-179.

Vandivier, R. W., Ogden, C. A., Fadok, V. A., Hoffmann, P. R., Brown, K. K., Botto, M., Walport, M. J., Fisher, J. H., Henson, P. M., and Greene, K. E. (2002). Role of surfactant proteins A, $\mathrm{D}$, and Clq in the clearance of apoptotic cells in vivo and in vitro: calreticulin and CD91 as a common collectin receptor complex. J. Immunol. 169, 3978-3986

Vegh, Z., Goyarts, E. C., Rozengarten, K., Mazumder, A., and Ghebrehiwet, B. (2003). Maturationdependent expression of $\mathrm{Clq}$ binding proteins on the cell surface of monocyte-derived dendritic cells. Int. Immunopharmacol. 3 , 345-357.

Vegh, Z., Kew, R., Gruber, B., and Ghebrehiwet, B. (2005). Chemotaxis of human monocyte derived dendritic cells toward $\mathrm{Clq}$ is mediated by $\mathrm{gClqR}$ and $\mathrm{cClqR}$. Mol. Immunol. 43, 1402-1407.

Walport, M. J., Davies, K. A., and Botto, M. (1998). Clq and systemic lupus erythematosus. Immunobiology 199, 265-285.
Wong, G. W., Wang, J., Hug, C., Tsao, T.-S., and Lodish, H. F. (2004) A family of Acrp30/adiponectin structural and functional paralogs. Proc. Natl. Acad. Sci. U.S.A. 101, 10302-10307.

Yonemasu, K., Stroud, R. M., Neidermeier, W., and Butler, W. T. (1971). Chemical studies on $\mathrm{Clq}$ a modulator of immunoglobulin biology. Biochem. Biophys. Res. Commun. 43, 1388-1394.

Conflict of Interest Statement: The authors declare that the research was conducted in the absence of any commercial or financial relationships that could be construed as a potential conflict of interest.

Received: 02 February 2012; accepted: 01 March 2012; published online: 05 April 2012.

Citation: Ghebrehiwet B, Hosszu KK, Valentino A and Peerschke EIB (2012) The C1q family of proteins: insights into the emerging non-traditional functions. Front. Immun. 3:52. doi: 10.3389/fimmu.2012.00052

This article was submitted to Frontiers in Molecular Innate Immunity, a specialty of Frontiers in Immunology.

Copyright (c) 2012 Ghebrehiwet, Hosszu, Valentino and Peerschke. This is an openaccess article distributed under the terms of the Creative Commons Attribution Non Commercial License, which permits non-commercial use, distribution, and reproduction in other forums, provided the original authors and source are credited. 